\title{
Las fuentes cubanas del Nuevo diccionario de la lengua castellana, de Vicente Salvá*
}

\author{
The Cuban sources of the Nuevo diccionario de la lengua \\ castellana of Vicente Salvá
}

ARMANDO CHÁVEZ-RIVERA

University of Houston Victoria

ChavezRiveraA@uhv.edu

Resumen: El filólogo y editor valenciano Vicente Salvá elaboró una edición mejorada del diccionario académico de 1843, la cual publicó bajo el título de Nuevo diccionario de la lengua castellana (1846). Salvá corrigió el diccionario de la RAE, pero a la vez le incorporó una muestra de voces regionales provenientes de Hispanoamérica. Salvá seleccionó numerosos cubanismos a partir de dos diccionarios elaborados en la isla, pero también se apoyó en otras fuentes escritas y orales. Este artículo se enfoca en esas fuentes y la selección de voces hecha por Salvá.

Palabras clave: lexicografía; regionalismo; colonial; Cuba; Hispanoamérica.

Abstract: Valencian philologist and editor Vicente Salvá made an improved edition of the 1843 academic dictionary, which he published under the title of Nuevo diccionario de la lengua castellana (1846). Salvá edited the RAE dictionary, and at the same time incorporated a sample of regional voices from Spanish America. Salvá selected many Cubanisms from two dictionaries compiled on the island, but also included information from other written and oral sources. This article focuses on those Cuban sources and several voices selected by Salvá.

Key words: lexicography; regionalism; colonial; Cuba; Spanish America.

Fecha de presentación: 07/05/2019 Fecha de aceptación: 23/03/2020

\section{INTRODUCCIÓN}

El gramático, bibliógrafo y librero Vicente Salvá (1786-1849) preparó a mediados de la década de 1840 una edición corregida y aumentada de la novena edición del Diccionario de la lengua castellana, que había sido publicada por la Real Academia Espa-

\footnotetext{
* Agradezco al Centro Kluge que me brindó patrocinio como académico residente en la Biblioteca del Congreso de los Estados Unidos, lo cual me permitió concluir esta investigación y otras sobre lexicografía hispánica.
} 
ñola en 1843. El Nuevo diccionario de la lengua castellana (NDLC) (1846) anuncia en la portada que «comprende la última edición íntegra, muy rectificada y mejorada, del publicado por la Academia Española, y unas veinte y seis mil voces, acepciones, frases y locuciones, entre ellas muchas americanas» (iii) ${ }^{1}$. Llamativamente, una de las más amplias representaciones de voces provinciales en ese diccionario son las que circulaban entonces en Cuba y las cuales estuvieron al alcance de Salvá gracias a su contacto directo con libros, manuscritos e intelectuales de la isla.

La información sobre Cuba incluida en el $N D L C$ forma parte de campos semánticos tan diversos como flora, fauna, agricultura, ganadería, así como aparatos y utensilios de trabajo. La producción azucarera es uno de los campos mejor representados, con voces específicas sobre aspectos agrícolas y técnicos. El NLDC permite divisar al trasluz la sociedad cubana de la época, gracias a esporádicas descripciones de comidas, bebidas y frutos, y hasta el registro de voces de tono jocoso y mordaz para fustigar apariencia física, conductas y errores humanos. Varios de los términos hacen énfasis en los recursos naturales emblemáticos del país, como si de ese modo dieran continuidad a imágenes de feracidad y abundancia propagadas sobre el Caribe desde los inicios de la conquista y la colonización.

Salvá tuvo a la vista dos documentos cubanos, a partir de los cuales seleccionó lemas y redactó artículos lexicográficos, a veces combinando contenidos y, en otras ocasiones, inclinándose más a favor de una de las dos fuentes. No voy a internarme en describir las circunstancias políticas que contribuyeron a que el filólogo valenciano tuviera acceso a esos textos porque ya ha sido motivo de un artículo publicado en $2017^{2}$. Tampoco voy a analizar el tratamiento de palabras, locuciones y frases en la macroestructura y microestructura del $N D L C$ porque es tema de un estudio de mi autoría en vías de publicación. Por tanto, las páginas siguientes exponen fundamentalmente cómo fue la reelaboración y copia textual de información en función de insertar provincialismos de la isla en el $N D L C$.

\section{EL ACCESO A LAS FUENTES PROCEDENTES DE CUBA}

El Diccionario provincial de voces cubanas (en adelante DPVC) publicado en 1836 por el escritor, geógrafo y cartógrafo Esteban Pichardo (1799-1879) ha pasado a la historia como el primero que fuera impreso dedicado exclusivamente a regionalismos de un país hispanoamericano, $\mathrm{Cuba}^{3}$. Sin embargo, otra obra con ese mismo objetivo ya había sido elaborada en La Habana, como confirma la existencia del manuscrito del diccionario «Provincialismos de la Isla de Cuba» (aludido a partir de ahora como «DPIC»), preparado por cuatro miembros de la Comisión Permanente de Literatura, parte de la Sección de Educación de la Real Sociedad Patriótica de La Habana (en adelante, mencionada como SEAP). La redacción del documento estuvo a cargo de Fran-

\footnotetext{
${ }^{1}$ Las citas del $N D L C$ incluidas en este artículo corresponden a la edición del $N D L C$ en 1846.

${ }^{2}$ Véase artículo de Chávez-Rivera (2017) citado en la bibliografía.

${ }^{3}$ Luego de la primera edición de 1836, Pichardo presentó tres ediciones enriquecidas: Diccionario provincial casi razonado de voces cubanas (1849), Diccionario provincial casi razonado de vozes cubanas (1861) (reimpreso en 1862) y Diccionario provincial casi razonado de vozes y frases cubanas (1875).
} 
cisco Ruiz, exdiscípulo y amigo del influyente prelado Félix Varela $(1788-1853)^{4}$, quien, al igual que Salvá, fue diputado ante las Cortes de Cádiz. Ambos votaron por la suspensión de poderes de Fernando VII, lo cual en 1823 costó a los diputados constitucionalistas la condena a muerte al suspenderse la Constitución de Cádiz (1812) y restaurarse el absolutismo. Varela optó por refugiarse inicialmente en Filadelfia y Salvá, en Londres y luego en París ${ }^{5}$.

El «DPIC» ostenta el valor adicional de ser resultado de un trabajo en colaboración de intelectuales habaneros, en el contexto de su propia comunidad. Lamentablemente, las pugnas políticas entre miembros de la SEAP y las presiones del gobierno colonial contra el surgimiento de la Academia Cubana de Literatura influyeron en que el manuscrito quedara sin publicar, pese a que la Comisión Permanente de Literatura de la SEAP había anunciado a mediados de diciembre de 1831 el propósito de imprimirlo en 1832.

$\mathrm{El}$ «DPIC» incluye americanismos de carácter enciclopédico, indigenismos y palabras del español revestidas de nuevas acepciones en la isla. Deviene así repertorio dialectal dedicado a la variante cubana del español; es una obra original, independiente, sin subordinación a otra. En total suman 677 lemas en el cuerpo principal del documento. La obra se enriquece debido a la formación filológica y multidisciplinaria de los colaboradores y a causa de que estos integraban instituciones desde donde se trabajaba a favor del progreso, la educación y la cultura en la isla. Varios de esos personajes fueron miembros del grupo intelectual liderado por Domingo del Monte (1804-1853) y gestaron un valioso corpus de textos de diversos géneros y con muestras de arraigo por la isla. El propio Del Monte se mantuvo personalmente al tanto de la elaboración del «DPIC» y presumiblemente aportó una relación de provincialismos que había hecho en 1827 durante una visita a Madrid. Además, brindó apoyo institucional desde su posición de secretario de la Sección de Educación de la SEAP.

Un aspecto decisivo es que tanto Salvá, como los autores de los dos registros de cubanismos, habían tenido un mismo modelo: el diccionario de la RAE. Esto fija un paradigma de trabajo en cuanto a la macroestructura y la microestructura, así como en el uso de abreviaturas con información metalingüística y símbolos. El «DPIC» toma como referente el DRAE 1822; Pichardo, el DRAE 1832; y Salvá, como he dicho, el $D R A E$ 1843. No obstante, las dos obras cubanas reajustaron las abreviaturas a sus pro-

\footnotetext{
${ }^{4}$ Este documento se encuentra actualmente aprobado para publicación por la Academia Norteamericana de la Lengua Española, con estudio introductorio y notas de Armando Chávez-Rivera.

${ }^{5}$ Varela fue uno de los primeros en publicar, en la revista literaria habanera Bimestre Cubana, con circulación también en ciudades estadounidenses, una reseña elogiosa sobre la gramática de Salvá.

${ }^{6}$ Del Monte nació en Venezuela y fue llevado a Cuba en la infancia. En La Habana, estudió leyes y se casó con una integrante de una de las familias más acaudaladas de la burguesía azucarera. Se convirtió en influyente intelectual desde finales de la década de 1820 y cultivó una amplia red de contactos con personajes de Estados Unidos y Europa. Poseía una selecta biblioteca con ediciones europeas y norteamericanas; instaba a sus contemporáneos a escribir y publicar, organizando para ello tertulias, evaluando manuscritos y editando. A inicios de 1844, arribó a Francia proveniente de los Estados Unidos para pasar algunos meses, pero imprevistos familiares y políticos lo retuvieron en París hasta mayo de 1846. Su relación con el gobierno colonial en La Habana se había ido tensando al extremo de que, a finales de abril de 1844, el capitán general de la isla había ordenado la detención de Del Monte y otros supuestos implicados en una conspiración antigubernamental. Del Monte se radicó en España y nunca más retornó a Cuba.
} 
pósitos y no reprodujeron pasivamente las que aparecían en el $D R A E$. Es preciso recordar que en fecha tan temprana como 1795, en la SEAP el fraile mercedario José María Peñalver hizo una exhortación a favor de elaborar un diccionario de provincialismos cubanos, tomando como referente la dinámica de trabajo adoptada por la RAE y el modelo establecido en Autoridades ${ }^{7}$.

La preparación en Cuba de registros como el «DPIC» y el DPVC hace recordar los orígenes de la RAE, cuando hubo una voluntad similar en España de realzar el orgullo nacional en el contexto europeo mediante la ejecución de obras dedicadas a la lengua y la literatura del país, y especialmente, luego de que la Academia Francesa y la Academia della Crusca ya habían presentado sus respectivos diccionarios. A tono con esos antecedentes, el «DPIC» y el $D P V C$ exponen ufanamente riquezas y potencialidades de la isla caribeña, con la ambición de que fueran apreciadas por otras naciones e incentivaran el comercio. La confección de estos registros lexicográficos por intelectuales arraigados en el área capitalina da cuenta de la maduración de la sociedad, la economía y la identidad nacional.

Por tanto, el «DPIC» y el DPVC comparten varias circunstancias: fueron preparados en un mismo ámbito geográfico, el occidente de Cuba, en la década de 1830, tomando como referente los diccionarios de la RAE y dirigidos al público local, pero también teniendo en cuenta una potencial audiencia foránea. Como favorable telón de fondo, varios narradores y poetas que gestaban sus obras en la década de $1830 \mathrm{se}$ empeñaron en incluir voces propias del país, en especial indigenismos, para patentizar su arraigo y orgullo por la isla.

Entre los objetivos de esos mismos intelectuales estuvo fomentar contactos e intercambios con personalidades de Europa y Norteamérica, tanto para recibir publicaciones como para darse a conocer en espacios editoriales, literarios y políticos de otros países. Por consiguiente, en las décadas de 1830 y 1840, Salvá era conocido como editor en La Habana, adonde llegaban las publicaciones de su casa en París y estas eran anunciadas positivamente. En el prólogo del $N D L C$, el valenciano declara que se había sentido afortunado de haber consultado el Diccionario provincial de voces cubanas, de Pichardo, y al editor, crítico y bibliófilo Del Monte, que le ayudó a resolver «varias dudas» (xvii). Asimismo, confiesa: «he disfrutado otro manuscrito, hecho por algunos habaneros de instrucción» (xvii). Tal como he constatado durante mis investigaciones, ese manuscrito que tuvo Salvá en sus manos fue en verdad el «DPIC», que fuera enviado de La Habana a Francia en abril de 1845, gracias a las gestiones de Del Monte.

El NDLC acoge lemas y acepciones procedentes sobre todo del occidente de la isla y la zona de la capital, donde fueron gestadas estas dos fuentes metalingüísticas de las que dispuso Salvá. En específico, la mirada del «DPIC» sobre la isla se tiende desde La Habana, lo cual queda expresado mediante una distancia subjetiva hacia el resto del territorio. La Habana era el núcleo urbano preponderante, sede de las instituciones políticas, con una amplia bahía habilitada para el comercio y punto de escala de las flotas en su viaje trasatlántico. En el documento resalta el claro protagonismo del occi-

${ }^{7}$ Véase «Memoria que promueve la edición de un Diccionario Provincial de la Isla de Cuba», de José María Peñalver. 
dente isleño y la urbe capitalina, entonces rodeada de tierras fértiles y prósperos campos azucareros. La Habana se convierte en el sitio simbólico desde donde se interpreta a la colonia y desde el cual se registran las variantes diatópicas, infiriendo que son de conocimiento extendido. A un lector aguzado como Salvá se le hizo evidente que el «DPIC» agrupaba términos de uso preponderante en el occidente cubano y los cuales, a modo de propicia confirmación adicional, a veces aparecían referidos en el diccionario de Pichardo como de uso exclusivo o predominante en el occidente y La Habana.

Por otra parte, la introducción del $D P V C$ establece claramente que el propósito no es recoger «las palabras estampadas en el Diccionario castellano: á ménos que signifiquen cosas diversas ó tengan aquí distintos nombres, ó bien cuando alguna circunstancia singular lo ecsija por ser propias del país, por error \& [sic]» (4). Es importante apreciar que el propio Pichardo expresa su deseo de que la contribución del DPVC fuese «digna de incluirse en el Diccionario general de la Real Academia á semejanza de los provincialismos de Andalucía, Murcia \&. [sic]» (5). Imbuido en ese deseo de precisión y notoriedad, Pichardo registró los vocablos existentes en zonas diversas de la isla para lo cual tuvo informantes y fijó contornos geográficos en diversos artículos a partir de una subdivisión geográfica explicada en la introducción:

hay ciertas producciones, voces, usos y acepciones diferentes en la misma isla; un Departamento adopta tales ó cuales, y para explicarlo añado «en la parte oriental, central ú occidental» contrayéndome á los tres Departamentos conocidos y entendiéndose el rigor de la palabra, uso, en la capital respectiva; otras veces me valgo de la espresion común «tierra-dentro, lo interior» esto es, desde el gobierno de Trinidad y Cienfuegos, hasta el de Bayamo inclusive; ó bien digo «en el vueltarriba, en la vueltabajo» que ya se entiende toda la parte del Este ó del Oeste divididas por los gobiernos de Trinidad y Cienfuegos inclusos en la primera; aunque por ecselencia muchos llaman vueltabajo solamente el territorio de Filipinas hasta cerca de la Habana. [sic] (4).

Esta clasificación es de fácil comprensión incluso para quien no conociese las principales localidades de la isla. Vale recordar que Pichardo se consagró a la geografía y la cartografía en función de confeccionar mapas que siguen siendo de referencia en esas disciplinas.

Pichardo reafirma su interés por cubrir el léxico a lo largo del país al enmarcar geográficamente definiciones, como la dedicada a mate, en que detalla que «en toda la isla se da este nombre á dos especies de granos [...]; en la vueltabajo la palabra sola MATE se entiende el colorado, y el amarillo se llama GUACALOTE [...]. El MATE CALENTURA, nombrado así en Puerto-Príncipe, tiene el color azul claro-cenizoso» [sic] (176) y en ese mismo artículo termina refiriéndose a que «en el vueltabajo se usan también por equivalentes las bolas» (176) y remitiendo a BOLAS, que aparece definida como «piedras esféricas del tamaño de la cereza mas ó menos, que usan los muchachos en lugar de mátes para sus juegos» [sic] (36-37). El NDLC incluye en el artículo sobre mate una acepción marcada como provincialismo cubano: «semilla redonda de un bejuco de este nombre, que sirve á los muchachos en lugar de bolitas para sus juegos» [sic] (701). O sea, Salvá resume información y combina contenidos de dos artículos del diccionario de Pichardo sin internarse en precisiones sobre el uso en diversas regiones isleñas. 
En cuanto a palanqueta el DPVC afirma que es «dulce seco, grosero, que hacen en la Habana de mais tostado y molido, amasado con miel y en figura de tal» (192). Años después, el $N D L C$ incluyó la acepción sin alusión a esa capital, sino en general como un provincialismo cubano. Asimismo, el DPVC define pechicato-ta con los sinónimos de «miserable, cicatero» (200) y especifica: «en la parte occidental es más usado gritando los muchachos al padrino de bautismo con este adjetivo cuando no reparte monedas» (200). Siguiendo el mismo método de trabajo, el NDLC introduce pechicato-ta definido exactamente con los mismos dos sinónimos utilizados por Pichardo, pero sin ningún detalle adicional sobre su uso en el occidente isleño. Salvá trabaja del mismo modo con el «DPIC». Entra cacalote en el NDLC con información tomada al pie de la letra del «DPIC»; solamente queda omitida la precisión de que la segunda acepción, «absurdo o disparate notable», se utiliza, según el «DPIC», en el «int. de la I. de Cuba»; o sea, en el interior de la isla, expresión usada en alusión a localidades alejadas de La Habana.

El $D P V C$ resulta pródigo en brindar detalles sobre el uso de determinadas voces en regiones del país, a las cuales alude como vueltabajo o vueltarriba, en unas veinte y cuarenta veces, respectivamente. En cambio, el «DPIC» nunca cita vueltabajo ni vueltarriba $\mathrm{y}$, en todo caso, se refiere vagamente a un supuesto «interior» de la isla. Por tanto, cabe deducir que la prioridad de Salvá, cuando optaba por hacer alguna especificación adicional sobre el uso de un término dentro de un área de Cuba, era en todo caso para apuntar el uso en La Habana, probablemente por la relevancia de esta como capital y puerto de escala entre España y América.

De ahí que algunos lemas incluidos en el $N D L C$ hagan referencia a voces usadas en La Habana, por ejemplo, cuico y guachinango, insertos como apodos que los habaneros daban a los mexicanos; caspiroleta, como un tipo de conserva de consistencia y de color canela hecha en La Habana; hicácos, como una fruta del tamaño de una nuez redonda y se agrega la precisión de que «con ella se hace un dulce muy estimado que suelen traer de la Habana á Europa» (583). Por otra parte, se acredita el uso en La Habana de charamusca, como una variante del lema charamasca, marcada en el NDLC como anticuada en España y definida como 'chamarasca'. Las referencias a La Habana en el $N D L C$ parecen ajustarse a un imaginario que vinculaba entonces a La Habana y su bahía con todo lo referente al archipiélago de Cuba. Era común en la época asociar el nombre de la capital con las zonas de la colonia más pobladas, de mejores caminos y con mayor desarrollo.

\section{LA SELECCIÓN DE CUBANISMOS}

Durante su estancia en París, a mediados de la década de 1840, Del Monte visitaba a la familia Salvá, según corrobora la invitación escrita por Salvá padre para que este se detuviera por su despacho para consultas lexicográficas. De modo muy concreto se pueden apreciar detalles del intercambio de Del Monte y Salvá con respecto a los preparativos del $N D L C$. En una misiva del 20 de enero de 1845, solicita información a Del Monte sobre el uso de los términos frijol y judia: «dos cosas se me ofrecen preguntar á V. sobre la voz frijol: la primera si pronuncian Vms. Fríjol ó Frijól, y la segunda, si entienden por ello lo q.e en España llamamos judía (hanicot en francés), o lo q.e decimos garvanso (pois para los franceses)» (Centón epistolario vol. 3, 357). Adicional- 
mente, el valenciano explica en el prólogo del $N D L C$ su método para determinar cuáles palabras eran americanismos. En ese sentido, relata prolijamente que concluyó que frijol era un provincialismo americano, que significaba lo mismo que judía, luego de consultar a «un mejicano, un chileno, un venezolano y un habanero» (XXVIII).

El trabajo de Salvá con los dos textos procedentes de Cuba y, además, con Del Monte, como fuente oral, escritor, editor y crítico con conocimiento del español americano, sirvieron para: identificar vocablos con acepciones exclusivas de la isla caribeña o comunes en territorios continentales. Asimismo, algunas palabras añadidas al $N D L C$ tienen la condición de enciclopedismo americano y algunas que son definidas como propias de «ambas Américas», por ejemplo, el árbol y su fruto conocidos como caimito o el árbol quiebrahacha, los cuales están presentes en las dos fuentes cubanas.

Salvá contempló solamente como cubanismos palabras que eran también de uso entonces en otros países o viceversa; pero en esos casos probablemente no dispuso de otras fuentes para poder corroborar cuáles eran voces de circulación restringida o más amplia geográficamente, por ejemplo, arepa, que aparece en el «DPIC» como especie de torta frita de harina de maíz y que es definida en el $N D L C$ solamente como «empanadita hecha de harina de maíz con carne de puerco dentro, que venden las negras en las esquinas de Cartagena de Indias, y es el almuerzo general de sus habitantes» (95). Salvá no deja constancia de que ese sustantivo también designaba un determinado alimento en Cuba, como probaban los folios del «DPIC», que estaban al alcance de su vista.

Hay que recordar que Salvá también utilizó fuentes como el Diccionario geográfico-histórico de las Indias Occidentales ó América, de Antonio de Alcedo, y que, como exquisito bibliófilo y coleccionista, disponía de publicaciones impresas en el Nuevo Mundo, según revela el catálogo de su biblioteca publicado años después, en dos volúmenes, por su hijo, Pedro Salvá. Se puede sopesar mejor la magnitud de su empeño lexicográfico si observamos la limitada cantidad de americanismos presentes en otros diccionarios de la época e inclusive la reticencia de la RAE a incluirlos en sus inventarios. Los contenidos de los dos textos cubanos debieron resultarle providenciales para redondear definiciones, compilar frases y locuciones y corroborar detalles. Las dos fuentes habían sido desarrolladas de manera independiente; no he encontrado ninguna evidencia de que Pichardo tuviera noticias del «DPIC», ni de que lo haya consultado.

El NDLC incluye 374 unidades con la marca de $p$. Cub. Además, en 19 artículos se hace mención a la isla de Cuba y en otros ocho hay menciones a La Habana o los habaneros. Nunca aparece el gentilicio cubano en el diccionario. No voy a reproducir la lista de todos los provincialismos atribuidos por Salvá a Cuba; la mayoría de los cuales los encontró en los dos textos, aunque a veces con detalles divergentes en cuanto a la grafía, uso o definición. Salvá trabajó con las dos fuentes complementando información.

Varios lemas marcados en el $N D L C$ como cubanismos, o alguna de sus acepciones, figuran en el $D P V C$, pero no están en el «DPIC»: abeja criolla o de la tierra, ácana, aceituno-na, chino-na (s. v. china), chumbo-ba (s. v. chumbo), hicacos, lujar, estar a manos (s. v. mano), mantequillera, mantón, mataperico, mayoral, ocuje, ostión, Pancho-cha (s. v. pancho), paso, pintón, quitrín, relamido-da, remojo, sabichoso-sa, safra, 
al salto (s. v. salto), sitiero-ra, sitio, socucho, songa, songuita, torcer, triache, vega, velorio, verraquera y visera.

El DPVC, con 273 páginas, es mucho más amplio y detallado que el manuscrito de 67 páginas del «DPIC». Sin embargo, en esos folios Salvá encontró abundante información. Numerosas unidades léxicas en el $N D L C$ con alguna acepción marcada como cubanismo u otra variante gráfica figuran en el «DPIC», pero no están en el $D P V C$. Son las siguientes: afuetear, aguachento, aindiado, alilaya, amigo de gancho y rancho (s. v. amigo-ga) («DPIC»: amigo de rancho y gancho), anaina, ancheta, anjá, apachurrar, apolismar, apotrerar, arranquera, atolito, bajareque, baquetudo, bejuquera, biscornear («DPIC»: bizcornear), bitongo (niño), borococo, burujón, cacalote, cancharrazo, canículo, carrascal, caspiroleta (DPVC: cafiroleta, también incorporada por Salvá en el $N D L C$ ), cayuca (DPVC: cayuco, variante tomada también por Salvá), cicote (DPVC: sicote), cicotera, cicotudo-da (DPVC: sicotudo-da), cocotudo, cuico-ca, currican, chancletear, changa, changuear, changuero, chapeador-ra (DPVC incluye el verbo chapear y el sustantivo chapeo), charamuscar (DPVC: charamusca, considerada voz corrompida en el $D P V C$ ), chinchin, chiqueon-na (DPVC: chiquion-na, y se incluye además chiqueo y chiquear), chirriar, chispa, desgarrar (DPVC: esgarrar, y en ediciones posteriores aparece desgarrar como voz corrompida), desgarro (DPVC: esgarro, y en ediciones posteriores aparece desgarro como voz corrompida), destutanarse, embotijar, embullamiento, embullo, enciguatarse, encocorar, enjalmar, enjaminar, enjillarse, enterciar, enyerbarse, escarrancharse, escorroso, fajada (DPVC: fajar, como 'arremeter' o 'arrojarse'), fogaje, fogonadura, fotutazo, furnia, gago-ga, gaguear, gaguera, gambarse (DPVC: gambado-da), ganchete (a medio), gayola, gofio, grajiento, guanajada, guangarero, guasanguero-ra, guataquear, guisasal (DPVC: guisaso), ijal, jaquimon, jirimiquear, jorro (DPVC: horro), lambarero-ra, lampriazo, macuenco-ca («DPIC»: mancuenco), mansera, matrería, maturranga, meladura, melusa, mogomogo, mojinete, molejón, muleque (DPVC: muleco o mulecon), patojear, patojera, patojo-ja, patuleque, patulequear, pavana, pechicatería, penino, pichilingue, pitirrear, pitirreo, puyero-ra, quimbámbulas, rabiasca, ranchear, rebolisco, refitolero, requilorios, rufianada, rufiano, sambeque, sambumbiero, sudadero, tacuacha, tarantines, tembladura ( «DPIC»: tembladera), ternejal, tocororo (DPVC: s. v. tocoloro), tongonearse, tongoneo, torería, trisca, triscar, truyada, tumbadera, yayero, zacateca («DPIC»: s. v. sacateca).

Salvá detectó en el «DPIC» un conjunto de palabras que Pichardo no había recogido y las cuales tampoco tenían registros previos en los diccionarios de la tradición preacadémica, ni extraacadémica. $\mathrm{O}$ sea, son voces que probablemente habían entrado por primera vez en un registro léxico al ser incluidas en el «DPIC», aunque por ahora me queda pendiente hacer cotejos con el inventario inédito elaborado por un intelectual de la capital isleña, José del Castillo (1787-1861), reconocido por sus contemporáneos por su erudición y dominio de diversas lenguas. A partir de lo publicado por Salvá en el $N D L C$, Pichardo tomó varias palabras marcadas como provincialismos cubanos y las incorporó en las ediciones posteriores de su diccionario, dándole crédito al valenciano, pero en ocasiones cuestionando voces y definiciones. 
Apenas hay en el $N D L C$ alrededor de una decena de palabras con la marca $p$. Cub., las cuales no están en el «DPIC» ni en el DPVC, y son las siguientes: canica, capá, concuño-ña, culebrica-lla, guanero, negrada, pieza, placer, tusa (en su segunda acepción, metafórica), zafra (la variante safra aparece en las dos fuentes escritas cubanas). Resulta una incógnita cuáles fueron las fuentes de Salvá, cuando, por ejemplo, define que en Cuba se le llama metafóricamente tusa a «la mujer despreciable» (1084). Si bien esa información no se encuentra en las dos fuentes escritas, pudo haber sido aportada por Del Monte.

En contraste, Salvá encuentra un determinado término en las dos fuentes escritas y, sin embargo, otra fuente le aporta otra variante. En el NDLC aparece volante con entrada propia y, además, figura en otra entrada volanta, marcada esta como provincialismo de La Habana para calesín muy ligero. En ese artículo sobre volanta, Salvá expresa duda de que en realidad a ese vehículo se le llame así, en vez de volante. Curiosamente, sobre este asunto entra al $N D L C$ la voz en primera persona del autor para enfatizar: «no creo que se llame así» (1122). Su incredulidad pudo deberse a que las dos fuentes escritas cubanas solamente recogían volante; por tanto, otra fuente escrita u oral aportó la variante volanta, la cual en verdad era de uso en esa ciudad. Adicionalmente, el artículo sobre volante incluye volanta con la marca de provincialismo de Cuba.

Un aspecto curioso es que una voz que ya se encontraba en desuso en España en el siglo XIX, y se había mantenido en uso en territorio americano, es recogida en una de las dos fuentes cubanas e incorporada por Salvá como americanismo. Se trata de torería, la cual es incluida en el $N D L C$ como $p$. Cub. bajo la definición de «travesura de gente joven» (1059). No aparece en el DPVC, pero sí en el «DPIC» como «lo mismo que travesura, hablando de jóvenes». El DRAE 1884 la incluye como cubanismo y, posteriormente, el DRAE 1925 esclarece la situación al marcarla como desusada y con la salvedad de su vigencia en América. Francisco Javier Santamaría (1942) comenta que es una antigua voz española y, de igual modo, Augusto Malaret (1931). Por otra parte, Fernando Ortiz (1923) explica que «efectivamente la voz aparece en los clásicos españoles y España perdió la voz pero que en Cuba se conservó» (65). Hoy en día, el $D L E$ le concede como tercera acepción 'travesura, calaverada' y la marca como desusada, aunque detectada en Bolivia, Costa Rica, Cuba, Ecuador y El Salvador.

Salvá actúa de modo diferente en cuanto al término gago. El NDLC lo marca como anticuado y lo define con el sinónimo de tartamudo, contenido presente en el DRAE 1843, a lo cual Salvá agrega entre corchetes que «está hoy en uso en la isla de Cuba» (539). Esta palabra cuenta con registro preacadémico desde Francisco del Rosal y, académico, desde Autoridades. De ese modo, el $N D L C$ informa sobre la vigencia de la voz fuera de España, internándose así en un aspecto diacrónico sobre la circulación de voces en el vasto territorio de la lengua española. Hoy en día, gago sigue siendo una voz de uso común en Cuba.

\section{ACEPCIONES AÑADIDAS A ARTÍCULOS PROVENIENTES DE FUENTES DE LA RAE}

Salvá utilizó varios signos especiales en el $N D L C$, pero al menos dos brindan información muy útil para detectar de un vistazo los artículos nuevos, corregidos, enriquecidos o reubicados en la macroestructura: la cruz $(+)$ indica adición de todo un ar- 
tículo al $N D L C$ y el asterisco $(*)$ hace constar que el artículo provenía del DRAE 1843 pero se le incorporó contenido entre paréntesis cuadrados. Por ahora, he identificado 270 artículos marcados al inicio con una cruz y, además, otros 107 que llevan el asterisco, para un total de 377 que incluyen la marca $p$. Cub. (usualmente una sola vez) u otra información sobre voces y realidades propias de la isla ${ }^{8}$.

A términos que estaban en el diccionario académico, el valenciano les agregó una acepción propia de Cuba. Al vocablo aguaitar, el cual originalmente aparecía en el DRAE 1843 como «acechar ó atisbar» con la marca de anticuada y la advertencia de que «hoy tiene uso entre gente vulgar», Salvá le sumó la acepción cubana de «ver sin ser visto y sin llevar malicia en ello» (NDLC 32). Sobre burujón, que ya aparecía en varias fuentes y llega al $D R A E 1843$ como «la hinchazon que se hace en la cabeza por algun golpe» [sic] (118), agregó una acepción cubana (tomada exactamente del «DPIC») como «porción de ropa envuelta de cualquier modo y sin orden» (NDLC 178). Dicha voz no aparecía en el diccionario de Pichardo de 1836, pero éste la adoptó en edición posterior

Veamos otros ejemplos. Canículo aparece en el Diccionario de autoridades (1729) como «cosa perteneciente y própria del Can, dicho oy Perro. Es voz inventada y jocosa» [sic] (115-116) y como «burlesca» en el diccionario del padre Esteban de Terreros y Pando (336). La voz desapareció del diccionario académico y Salvá la rescató en el $N D L C$ agregándole su uso cubano en el sentido de «mentecato» (202). En cuanto a fogonadura ya aparecía como en el DRAE 1843 con la marca técnica de ser del ámbito náutico y reproducida así en el $N D L C$ : «cada uno de los agujeros que tienen las cubiertas de la embarcacion, para que pasen por ellos los palos á fijarse en la sobrequilla» (NDLC 524), a lo cual Salvá añade que es usada en Cuba en referencia a «la parte de un horcon ó poste que se mete debajo de tierra, y la cabeza de una viga que se introduce en la pared» (524). $\mathrm{Al}$ respecto, la definición asentada como cubanismo por Salvá está basada casi textualmente en el «DPIC»; el término no aparecía en el inventario de Pichardo.

Algunos lemas y locuciones que fueron incluidos en los folios del «DPIC» ya estaban en el DRAE 1822 como patrimonio del español general y se mantenían en la edición de 1843, por ejemplo: jamona, rechoncho y hacerse el sueco. Salvá reproduce los artículos relacionados con esos términos tal cual aparecen en el DRAE 1843, sin hacer ningún reajuste. Esto deja en evidencia que ocasionalmente los redactores del «DPIC» incluyeron en su registro algunas palabras y locuciones que se usaban en Cuba, aunque circulaban con el mismo sentido en otros territorios americanos y en el peninsular, lo cual prueba la ya mencionada presencia de los mismos en el DRAE 1822. O sea, por momentos los habaneros tendieron a preparar un diccionario integral, incluyendo voces que no eran de uso exclusivo en la isla, a pesar de que supuestamente el manuscrito, para ser coherente con su título, debió haber restringido la nomenclatura a provincialismos. Sabemos que en obras lexicográficas realizadas mediante esfuerzo colectivo

\footnotetext{
${ }^{8}$ En el NDLC 1846 los signos especiales y su correspondiente significado están explicados en las «Advertencias para el uso de este diccionario», en la página XL, mientras que antes, en la página XXI, aparece la nota 47, con la explicación para distinguir adición, reorganización o corrección de contenidos.
} 
(como Autoridades) en ocasiones el resultado es más amplio de lo estrictamente estipulado al inicio como propósito rector.

Otros lemas que ya estaban en el DRAE 1843 y que el $N D L C$ reproduce agregando alguna acepción marcada como cubana son, por ejemplo: calambuco, refitolero y regatear. Además, al artículo dedicado a patojo, recogido por la tradición académica como «el que tiene los pies ò piernas torcidos ù desproporcionados, y remeda al pato en andar meneando el cuerpo de un lado y otro» [sic] (Autoridades 165) y reproducido en el $D R A E$ 1843, Salvá le agrega, en el mismo sentido, una acepción, con marca de cubanismo: «el que tiene los piés torcidos hacia afuera por el tobillo» (NDLC 812). En cambio, incluye una acepción con marca de americanismo para potrero, que ya estaba en el DRAE 1843 como «el que cuida de los potros cuando están en la dehesa» [sic] (580) y que Salvá encuentra en las dos fuentes cubanas, en el sentido de «especie de dehesa cerrada y destinada principalmente a la ceba de ganado mayor y a la siembra de maíz y otros frutos» («DPIC»).

Sobre jorro, presente en el DRAE 1843, Salvá agrega una acepción: «adj. m. con que se designa en la isla de Cuba el tabaco que no arde por su mala calidad» (636). En cuanto a un objeto como el sudadero, que tenía en el DRAE 1843 varias acepciones y una de ellas: «en los caballos manta que se les pone debajo de la silla» (679), Salvá toma esa misma información y añade otra complementaria, procedente de fuentes cubanas, al decir: «en la isla de Cuba es un cojin hecho de lana ó junco para el mismo fin» (NDLC 1018).

La palabra sabana, que aparecía en el DRAE 1843, llega enriquecida al $N D L C$ con un detalle revelador en cuanto a información coincidente con la del «DPIC» y el $D P V C$. El artículo del DRAE 1843 dedicado a sabana es reproducido por Salvá y le agrega información entre paréntesis cuadrados, del siguiente modo: «páramo, llanura extensa y arenosa sin árboles, [aunque suele abundar de buenos pastos]. Es voz de mucho uso en América» (968). Veamos la información presente en el «DPIC» y en el $D P V C$ en que se hace la salvedad de que son terrenos aptos para la ganadería:

Sabana. n. s. gran extensión de tierra despoblada de bosques p[o]r estéril, [tachón] aunq[u]e no á tal grado q[u]e carezcan absolutam[en]te de buenos pastos. [«DPIC»]

Sabana. N. s. f. vz. ind. Terreno limpio, llano, sin arboleda, donde pasta frecuentemente el ganado. Por lo comun presenta buen camino; pero se sufre el rigor del sol, $\mathrm{y}$, si es baja, en tiempo de lluvias desmiente aquella ventaja. [DPVC]

Algunas palabras que aparecen en el «DPIC» y el $D P V C$ fueron incluidas por Salvá en su $N D L C$ sin hacer ninguna distinción diatópica, tal es el caso de alepín y cebruno («DPIC»: s. v. sebruno). Posiblemente eran términos de amplia circulación en la época; Salvá pudo reparar en ellos y tomarlos para el $N D L C$ sin que fuese preciso añadir información alguna sobre un ámbito geográfico en específico. Asimismo, el NDLC incluye palabras derivadas cuya base ya estaba en el DRAE. El NDLC inserta zapotal como «el campo poblado de zapotes» (1135), sin marcarla como cubana ni restringir su uso regional, y la cual aparece en el «DPIC» como sapotal. El DRAE 1843 solamente incluía el sustantivo zapote. 
Hay acepciones genuinamente cubanas en el «DPIC» o en el DPVC, a veces con presencia en ambos, pero que Salvá no incluye en su $N D L C$. Por ejemplo: bocadillo, presente con tres acepciones en el DRAE 1843 y luego sin modificación en el $N D L C$; una de sus acepciones es en cuanto a alimentación: «entre los trabajadores del campo el alimento que suelen tomar entre almuerzo y comida, como á las diez de la mañana. Jentaculum» (158-159). Las fuentes cubanas coinciden en que en la isla se denominaba bocadillo a un «dulce en pasta muy delicado hecho de cidra, boniato, canela y otros ingredientes» («DPIC») y el DPVC confirma esa versión al describirlo como «dulce blando y muy suave, hecho de boniato» (36). Salvá, que por lo general se muestra interesado por platos de la cocina cubana y los incluye a lo largo del $N D L C$, paradójicamente, no expande la definición académica de 1843 sobre el bocadillo.

En algunas ocasiones, el $N D L C$ se refiere a la isla de Cuba, sea por una palabra que, sin ser voz diatópica, es usada en ese territorio o porque se refiere a un enciclopedismo. Esos casos, a menudo, tienen relación con plantas americanas, como ácana, aguinaldo, ateje, capá, daguilla, jagüey, majagua, ocuje y yarey.

\section{SIMILITUDES ENTRE ARTícULOS DEL NDLC Y LAS FUENTES CUBANAS}

Las similitudes en el contenido de artículos lexicales del «DPIC» y el $N D L C$ pueden constatarse en cuanto a términos como: bejuquera, curricán, destutanarse, fajada, guanajada, guataquear, guisasal, jorro, lampriazo, mansera, melusa, mojinete, palanquetero, pichilingue, pitirrear, rebolisco, sambeque, sumbarse, tacho, tarantines, tinglado, trisca, truyada, vianda, yayero. A pesar de todo lo revelado ya en páginas previas, veamos ejemplos muy elocuentes de ocasiones en que las fuentes cubanas les fueron tan fiables a Salvá que este ni siquiera optó por reelaborar contenidos, tal como puede observarse en los siguientes ejemplos (en lo que respecta al $N D L C$, cito los artículos de interés solo en sus porciones referidas a Cuba):

BURUJÓN. m. aum. de burujo. $\| p$. Cub. Porcion de ropa envuelta de cualquier modo y sin orden. $[N D L C]$

Burujon. n. s. Porcion de ropa embuelta de cualquier modo y sin orden. [«DPIC»]

CARRASCAL. m. El sitio ó monte poblado de carrascas. Ilicetum. [ll p. Cub. Sabana pedregosa y estéril donde solo crecen arbustos y malezas.] [NDLC]

Carrascal. n. s. Sabana pedregosa y esteril [tachón] donde solo crecen arbustos y malezas. $[\ll \mathrm{DPIC} »]$

COCOTUDO, DA. adj. $p$. Cub. El que tiene carácter firme é independiente. [NDLC] Cocotudo, a. n. adj. El q[u]e tiene caracter firme é independiente. [«DPIC»]

DESTUTANARSE. r. $p$. Cub. Matarse trabajando física ó intelectualmente, hasta ponerse en la piel y los huesos. I| met. $p$. Cub. Afanarse mucho por alguna cosa. [NDLC]

Destutanarse. v. n. Aniquilarse tanto con el trabajo, asi físico como intelectual, q[u]e le reduce á piel y huesos. Tambien en sentido fig. se dice del q[u]e se afana mucho p[o]r alguna cosa. [«DPIC»] 
FURNIA. f. $p$. $C u b$. Sumidero natural por donde corren las aguas que se recogen en los terrenos bajos. [NDLC]

Furnia. n. s. Sumidero natural $\mathrm{p}[\mathrm{o}] \mathrm{r}$ donde corren las aguas $\mathrm{q}[\mathrm{u}] \mathrm{e}$ se reunen en los terrenos bajos. [«DPIC»]

MOLEJON. m. $p$. Cub. Pedazo de piedra de amolar que aun no está montado. [NDLC]

Molejon. n. s. Trozo de piedra de amolar q[u]e no está montado. [«DPIC»]

PITIRREAR. n. $p$. Cub. Pedir con petulancia é importunidad. [NDLC]

Pitirrear. v. n. Pedir con petulancia é importunidad. [«DPIC»]

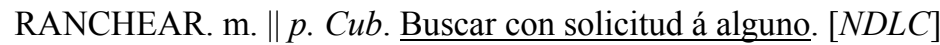

Ranchear. v. act. vulg. Buscar con solicitud á alguno. [«DPIC»]

RANCHERÍA. f. $\| p$. Cub. La reunion de negros cimarrones en los bosques y palenques. $[N D L C]$

Rancheria. n. s. La reunion de negros cimarrones en los bosques y palenques. $[\ll \mathrm{DPIC} »]$

TRISCAR. v. $\| p$. Cub. Burlarse de alguno con disimulo. [NDLC]

Triscar. v. act. Burlarse de alguno con disimulo. [«DPIC»]

En algunas ocasiones, Salvá encuentra la misma voz en las dos fuentes escritas procedentes de Cuba, pero se inclina por precisiones de una más que por la otra. La definición de manjarria del $N D L C$ se debe a la planteada en el «DPIC», aunque el DPVC también la define de modo bastante gráfico:

MANJARRIA. f. $p$. $C u b$. Gran palanca en los trapiches, que formando ángulo con el eje de la maza mayor, al cual está trabada, sirve para mover la máquina. [NDLC]

Manjarria. n. s. Gran palma en los trapiches q[u]e formando un angulo con el ege de la masa mayor al cual está trabada, sirve para mover la máquina. [«DPIC»]

MANJARRIA. N. s. f. Cada uno de los palos que en posicion oblicua vienen desde el centro de la parte superior del trapiche, de los cuales tiran los bueyes para que giren las mazas. [DPVC]

Difiere también la descripción entre el «DPIC» y el DPVC de macuto, pero Salvá transcribe casi textualmente la del «DPIC».

MACUTO. m. p. Cub. Paquetito hecho de yagua, que contiene cera, carne, tabaco etc. $[N D L C]$

Macuto. n. s. Paquetico hecho de yagua $\mathrm{q}[\mathrm{u}] \mathrm{e}$ contiene alguna cosa, como cera, carne, tabaco \&c. [«DPIC»]

MACUTO. N. s. m. Especie de saco largo y angosto tejido regularmente de guano. $[D P V C]$ 
En otros momentos, Salvá toma información del «DPIC» y del DPVC tanto para fijar dos acepciones o para construir una sola con elementos de ambas fuentes. Observemos, por ejemplo, que copia una primera acepción sobre enfermedad en los caballos recogida en las dos fuentes cubanas, pero la segunda, en referencia a un dulce casero, aparece solamente en el $D P V C$.

MASAMORRA. f. $p$. Cub. Enfermedad que padecen los caballos en la parte posterior del casco, ocasionada por la humedad o algun magullamiento. $\| p$. Cub. MAJARETE. [NDLC]

Masamorra. n. s. Enfermedad $\mathrm{q}[\mathrm{u}] \mathrm{e}$ padecen los caballos en la parte posterior del casco, ocasionada $\mathrm{p}$ [o]r la humedad o algun magullamiento. [«DPIC»]

MASAMORRA. N. s. f. Ampolla ó especie de apostema que sale á las caballerías en la parte inferior de los cascos, la que abierta al principio echa sanguaza y envejecida pus; cáusala la continua humedad ó fango. \| Véase MAJARETE. [DPVC]

De igual modo, ocurre en la construcción del artículo del NDLC sobre marchante, en que el $N D L C$ transcribe contenido de ambas fuentes de cubanismos, pero específicamente extrae el sinónimo maula del DPVC.

MARCHANTE. m. TRAFICANTE. $\| p$. And. [y Cub.] PARROQUIANO. $\|$ adj. MERCANTIL. || Bueno, de buena calidad ó de recibo. Se usa tambien ahora este adjetivo para la especie de abadejo, que por su mediana calidad se llama PESCADO MARCHANTE. [\| p. Cub. Solapado, maula.] [NDLC]

Marchante. n. s. Lo mismo q[u]e parroquiano. Tambien en sentido moral se aplica al $\mathrm{q}[\mathrm{u}] \mathrm{e}$ no es muy puro en sus procedimientos. [«DPIC»]

MARCHANTE. Com. La persona que acostumbra ó pacta comprar ó llevar relaciones siempre en una misma tienda, lugar \&. \| Tratamiento de menosprecio, sinónimo de MÁULA. [DPVC]

Salvá también conforma artículos tomando fragmentos del «DPIC» y del DPVC, por ejemplo, así se observa en ceja, en que el $N D L C$ incluye detalles como que es un área boscosa que no se tumba y, a la vez, se usa como camino, pero la precisión del uso de esa zona como camino emerge exclusivamente en el $D P V C$.

CEJA. f. $\| p$. Cub. La faja de un bosque que no se corta, y sirve de vereda ó camino. [NDLC]

Ceja. n. s. La pequeña parte de un bosque q[u]e no se tumba. [«DPIC»]

CEJA. N. s. f. Camino estrecho como vereda en un liston ó faja de bosque. [DPVC]

Sobre la inclusión de yagua en el $N D L C$ se observa que Salvá realiza una definición en términos muy similares al «DPIC» e incluye una locución presente en el $D P V C$.

YAGUA. f. $p$. $C u b$. f. La corteza que tiene la palma real en su follaje, la cual abraza y encierra al tallo, como la vaina á la semilla. Se desprende naturalmente del tallo que sale todas las lunas, y se aprovecha para embalar algunos objetos. || IRSE Á CORTAR YAGUA. fr. $p$. $C u b$. AMOSTAZARSE. [NDLC]

Yagua. n. s. Corteza q[u]e tiene la palma real en su follage, $\mathrm{q}[\mathrm{u}] \mathrm{e}$ abraza y encierra el tallo como la vaina, la cemilla. La arroja con la penca ú hoja, de la cual forma el gran pecciolo. [«DPIC»] 
YAGUA. N. s. f. vz. ind. Produccion de la palma real, que á manera de un cuero algo roscado está pegada á la penca; tiene regularmente 2 varas de largo y 1 de ancho; su grueso en el medio longitudinal es mas ó menos de $1 / 2$ pulgada, y va adelgazando hácia las orillas; es consistente, elástica, hebrosa á lo largo, blanca-amarillosa y suave por un lado y por fuera verde; aunque después oscurece. Todas las lunas se produce una YAGUA y penca: aquella cae naturalmente y se aprovecha para mil objetos, remojándose antes para volverle la elasticidad que pierde secándose: se emplea como envase para tercios de tabaco, catáuros, cubos, jáulas, techos y forros provicionales de edificios rústicos \&. II IRSE Á CORTAR YAGUA. Frase familiar que significa abochornarse, incomodarse por alguna chanza ó suceso trivial. [DPVC]

En este caso, se puede observar la inclusión en el $N D L C$ de una locución a partir del $D P V C$ y definida esta de modo sinonímico con un vocablo del español peninsular.

Estas amplias coincidencias de contenido en cuanto lemas y definiciones contribuyen a reafirmar lo que anteriormente he planteado y es que las fuentes cubanas poseían información lexicográfica amplia y apropiada para ser usada por Salvá, al punto de copiarlas textualmente, a pesar de que ni los habaneros miembros del equipo ejecutor del «DPIC» ni el propio Pichardo tuvieron la elaboración de esos registros como absoluta prioridad en su vida profesional. Todos ellos eran intelectuales con otras diversas facetas y ocupaciones que les proveyeron de una excelente carrera.

\section{REPERCUSIÓN EN LOS REGISTROS DE LA RAE}

Ciertas palabras aparecidas en el $N D L C$ y que provenían de Cuba fueron incluidas en el $D R A E$ 1925, por ejemplo, tinglado, presente en el «DPIC»y en el $D P V C$, fue tomada por Salvá para expandir el artículo que ya existía en el DRAE 1843 sobre ese lema sumándole una definición con marca de cubanismo. Es formulado en el NDLC de una manera muy parecida al «DPIC»y en esos términos ha perdurado hasta llegar al $D L E$.

TINGLADO. m. $\| p$. Cub. Un tablado inclinado sobre el cual cae la miel que purgan los panes de azúcar. [NDLC]

Tinglado. n. s. Un tablado inclinado sobre el cual cae y corre en razon del declive la miel q[u]e purgan los panes de azucar. [«DPIC»]

TINGLADO. N. s. m. Cualquiera obra de madera en que una orilla de la tabla va puesta sobre la de otra. [DPVC]

tinglado. m. Cuba. Tablado en ligero declive donde cae la miel que purgan los panes de azúcar. $[D L E]$

En este ejemplo anterior, se constata el influjo de las fuentes cubanas sobre el $N D L C$ y, por esta vía, en la entrada de voces en el diccionario académico.

Otras palabras fueron engastadas como cubanismos por Salvá en el $N D L C$ y en el siglo XX entraron en ediciones del $D R A E$ con marca de cubanismo, como sambumbiería. En cuanto a sambumbia, registrada por Salvá en el $N D L C$ y que apareció años después en el $D R A E$ 1884, figura hoy en día en el $D L E$ con marca de cubanismo. El lema mansera, presente en el «DPIC» y tomado por Salvá, no aparece en el DPVC, pero fue citado en 1875 por Pichardo haciendo referencia al NDLC. La palabra penetró 
en los registros de la RAE y la hallamos actualmente en el $D L E$. Vale observar las similitudes en la definición, desde el «DPIC», el $N D L C$ y el diccionario de Pichardo en la edición de 1875, hasta llegar al diccionario académico. Semejante evidencia confirma, una vez más, que el primer registro lexical preparado en la isla ha ejercido su influjo hasta la actualidad en contenidos del inventario académico.

MANSERA. f. $p$. Cub. La artesa que colocada bajo de las mazas del trapiche, recibe el zumo de la caña del azúcar. [NDLC]

Mansera. n. s. La artesa en q[u]e se recibe el guarapo ó zumo de la caña de azucar, colocada debajo de las masas del trapiche: tambien se llama bancazo. [«DPIC»]

Mansera. - n. s. f. -La esteva. \| Mansera. - La artesa que colocada debajo de las mazas del Trapiche, recibe el zumo de la Caña de azúcar (Diccionario de Salvá) [DPCRVFC, Pichardo, 1861]

mansera. 1. f. Cuba. Artesa que se colocaba debajo de las mazas del trapiche para recibir el jugo de caña. [DLE]

Sorprende que Salvá no haya incorporado algunos términos, pese a estar en las dos fuentes cubanas. En ese sentido, un caso notable es batey, por su condición de palabra indoamericana de larga data («DPIC»: s. v. batei). Bartolomé de las Casas y Gonzalo Fernández de Oviedo la habían recogido. El DRAE acoge la palabra en 1884. Para hacer justicia a Salvá, recordemos que varias obras importantes sobre la conquista y colonización de tierras americanas fueron publicadas en la segunda mitad del XIX, años después de la primera edición del $N D L C$.

Salvá incurre en algunas omisiones, imprecisiones y errores. Una falla en la transcripción lleva a registrar la locución correr jobos, definida como «hacer novillos» (NDLC 635), en vez de la forma correcta, comer jobos, que es como aparece entre trazos de difícil caligrafía en el «DPIC»y marcada como familiar. De igual modo, Salvá escribe tembladura y la define como 'tremedal', cuando en realidad el «DPIC» recoge tembladera, usada en Cuba en referencia a terreno cenagoso y casi intransitable. Asimismo, el valenciano incluye trasar, con una errata, en vez de transar, que es como aparece en el DPVC y se usa en Cuba por transigir. Sin dudas, fue un accidente en la composición tipográfica que omitió una consonante, pues el lema trasar aparece correctamente ubicado en el $N D L C$, entre transalpino y transbisabuelo. Por otra parte, aparece en el $N D L C$ la voz sino, con la definición tomada del «DPIC» para el lema sinc. O sea, la caligrafía y la tinta expandida sobre los folios jugaron malas pasadas a Salvá y lo llevaron a transcribir voces incorporándoles errores ortográficos. En otros casos, no se dejó amilanar por las tachaduras, por ejemplo, tomó embullamiento y carrascal, a pesar de que lema y definición quedaron tachados en el manuscrito.

En cuanto a la definición de burén en el $N D L C$, la misma está endeudada con la planteada en el «DPIC», pese a que Pichardo le dedica un artículo mucho más amplio en la primera edición de su diccionario. $\mathrm{El}$ «DPIC» alude tanto a alimentos hechos a partir de yuca y maíz, pero el $D P V C$ menciona solamente al uso del burén para cocer tortas de yuca, como si de ese modo se remontara a los orígenes precolombinos del burén, usado por la población indígena, la cual tuvo la yuca en su alimentación habitual. En Cuba, ya para la década de 1830, el burén se utilizaba también para cocer otros 
tipos de alimentos, como se describe en el «DPIC» y narraciones costumbristas de entonces. Salvá falla al decir que se trata de una vasija como vemos a continuación:

BUREN. m. $p$. Cub. Vasija de barro cocido, de forma circular en que se tuesta el cazabe y otras tortas de harina. [NDLC]

Buren. n. s. instrumento de barro cocido en forma circular para tostar el casabe, cocer las matahambres, tortillas de maiz y otros compuestos de harina. [«DPIC»]

BUREN. N. s. m. vz. ind. Especie de horno tendido en vez de bóveda, sobre el cual y en sus moldes se echa la yuca rallada y preparada para que el fuego compacte las tortas de casabe. [DPVC]

Otras definiciones e información del $N D L C$ también sorprenden, por ejemplo, la inclusión de una palabra tan distintiva de los mejicanos, como guacamole, presente en el «DPIC» pero añadida al $N D L C$ con marca de provincialismo de Cuba y sin ninguna alusión a México. La Habana mantenía en ese entonces un intenso vínculo comercial con Yucatán y, presumiblemente, otras palabras pudieron llegar a la isla por esa vía. No obstante, resulta desconcertante que Salvá, luego de definir velorio (marcada como provincialismo de Cuba y de México) como «la reunion de personas que velan á un difunto en la casa mortuoria» [sic] (1100), agregue: «si es un niño, hay baile y reina la alegría» (1100), lo cual dista de que ocurriese realmente en la isla. Adicionalmente, contribuye a llamar la atención sobre los vínculos de Cuba y México en ese entonces, la inclusión por Salvá de zacateca como 'sepulturero' y la hipótesis: «por haber sido tal vez en algun tiempo los que ejercian este oficio, indios zacatecas» [sic] (1131). La palabra no aparece en el $D P V C$, pero sí en el «DPIC», aunque con la información perifrástica de: «el que entierra los muertos».

\section{CONCLUSIONES}

Salvá se valió de fragmentos de fuentes cubanas aplicando su pericia en gestar, corregir y enriquecer diccionarios. Sus consultas a Del Monte forman parte de las redes de colaboración tendidas entre intelectuales europeos y americanos liberales establecidos o de paso en Londres y París. En medio de escenarios borrascosos, estos concretaron proyectos de colaboración. Persecución, exilio, arraigo por la patria y fervor por la lengua acercaron a estos intelectuales y los llevaron a trabajar en conjunto. A través de la definición y cotejo de palabras que reconocían como propias y de entrañable sonoridad se reafirmaban mientras vivían en otro país y otra cultura.

La selección de cubanismos para la elaboración del $N D L C$ resultó durante décadas un interrogante para lexicógrafos cubanos que no pudieron cotejar el contenido de ese diccionario con folios inéditos procedentes de La Habana que Salvá tuvo a la vista en París. La variedad y la pertinencia de varias inclusiones llamó la atención a Pichardo, quien refutó ríspidamente algunos contenidos del $N D L C$, pero no por ello dejó de tomar en cuenta algunos lemas y definiciones para citarlas en ediciones posteriores de su diccionario dándole crédito al valenciano. Asimismo, los aportes de Salvá fueron evocados a finales del siglo XIX e inicios del XX en los debates filológicos de la isla por José Miguel Macías (1830-1905) y Juan Miguel Dihigo (1866-1952), a su vez autores de inventarios léxicos. 
Las dos obras elaboradas en Cuba en la década de 1830 y la de Salvá revelan matices en cuanto al tratamiento de los regionalismos, la supuesta corrupción del español en regiones americanas, los prejuicios de clase social, raza y género, el reconocimiento del legado indígena, y las delimitaciones entre lo coloquial, familiar y vulgar. Los redactores del «DPIC» se ufanan del legado indígena y, además, a través de una amplia selección de voces familiares y coloquiales apuntan hacia el carácter de la sociedad habanera; el $D P V C$ revela la inquietud sobre matices del léxico en su contenido y descubre prejuicios de clase, raza y género, así como una tendencia normativa sobre el uso del idioma. El equipo ejecutor del «DPIC» y Pichardo emprendieron sus respectivas obras con la voluntad de dejar constancia del carácter de los habitantes de la isla en su expresión a través del lenguaje.

Por su parte, Salvá acopió voces coloquiales, familiares e ingeniosas con una flexibilidad que parece inclinada a captar la lengua en su uso vivo y cambiante en vez de dedicarse a censurar con juicio severo. El liberalismo de Salvá, demostrado en su vida política, parece hacerse evidente en el plano cultural y humanista durante la preparación del $N D L C$, al reconocer nuevas comunidades de hablantes del otro lado del Atlántico, e incluso poner la mirada en ellos como usuarios legítimos de la lengua y consumidores de productos culturales.

Las tensiones culturales y políticas descansan de forma sutil o explícitamente en la hechura de esas tres obras. Sus respectivos autores emprendieron la elaboración de registros léxicos replanteándose la relación con otras obras e instituciones canónicas, mirándolas con aceptación, reticencia o rechazo. Lengua, poder y política corrieron internamente en la gestación de estos inventarios léxicos, así como posteriormente, en su recepción.

\section{REFERENCIAS BIBLIOGRÁFICAS}

AhUMADA LARA, Ignacio (2000): Cinco siglos de lexicografia del español, Jaén, Universidad de Jaén.

AlCEDO, Antonio (1786-89): Diccionario geográfico-histórico de las Indias Occidentales ó América: Es á saber: de los reynos del Perú, Nueva España, Tierra Firme, Chile, y Nuevo Reyno de Granada, Madrid, Imprenta de B. Cano [etc.].

Álvarez de Miranda, Pedro (2011): Los diccionarios del español moderno, Gijón, Ediciones Trea.

AZORÍN FERNÁNDEZ, Dolores (2008): «Para la historia de los americanismos léxicos en los diccionarios del español», Revista de Investigación Lingüística, 11, pp. 13-43.

ChÁveZ-Rivera, Armando (2017): «Los vínculos de Vicente Salvá con Cuba: liberalismo, lexicografía y bibliofilia en el siglo XIX», en Entre la ética y la estética. Estudios en homenaje a Joan J. Gilabert, Newark, Delaware, Juan de la Cuesta-Hispanic Monographs, pp. 133-152.

ChÁVEZ-RiverA, Armando (2018): «El reflejo de voces de Cuba y del español general en obras de Richard Robert Madden», The Cincinnati Romance Review, 45, pp. 145160 . 
COVARRUBIAS y OROZCO, Sebastián (1611): Tesoro de la lengua castellana o española, Madrid, Luis Sánchez.

DiHigo, Juan Miguel (1928): Léxico cubano: contribución al estudio de las voces que lo forman. La Habana, Imprenta «El siglo XX».

Macías, José Miguel (1885): Diccionario cubano, etimológico, crítico, razonado y comprensivo, Veracruz, Imprenta de C. Trowbridge.

Malaret, Augusto (1931): Diccionario de americanismos, San Juan, Imprenta Venezuela.

MonTE, Domingo del (2002): Centón epistolario, La Habana, Imagen Contemporánea, 4 vols.

NeBRIJA, Elio Antonio de (1492): Diccionario latino-español, Salamanca.

NeBriJa, Elio Antonio de (1495): Vocabulario español-latino, Salamanca.

NúNEZ DE TABOADA, Melchior Emmanuel (1825): Diccionario de la lengua castellana, París, Librería de Seguin, 2 vols.

ORTIZ, Fernando (1923): Un catauro de cubanismos. Apuntes lexicográficos. Extracto de la Revista Bimestre Cubana, La Habana.

PeÑAlVER, José María (1977 [1795]): «Memoria que promueve la edición de un Diccionario Provincial de la Isla de Cuba», Antología de lingüística cubana, La Habana, Editorial de Ciencias Sociales, I, pp. 13-20.

PICHARDO, Esteban (1836): Diccionario provincial de voces cubanas, Matanzas, Imprenta de la Real Marina.

REAL ACADEMIA ESPAÑola (1726-1739): Diccionario de la lengua castellana [Diccionario de autoridades], Madrid, Imprenta de Francisco del Hierro.

ReAl ACADEMia EsPañola (1843): Diccionario de la lengua castellana, Madrid, Imprenta de F. M. Fernández.

REAL ACADEMia ESPAÑola (2014): Diccionario de la lengua española, Madrid, https://dle.rae.es/

REIG SALVÁ, Carola (1972): Vicente Salvá: un valenciano de prestigio internacional, Valencia, Instituto de Literatura y Estudios Filológicos.

RosAL, Francisco (1611): «Origen y etimología de todos los vocablos originales de la lengua castellana», Nuevo tesoro lexicográfico de la lengua española, Madrid, RAE.

SAlvÁ, Pedro (1872): Catálogo de la biblioteca de Salvá, Valencia, Imprenta de Ferrer de Orga, 2 vols.

SAlvÁ, Vicente (1847): Nuevo diccionario de la lengua castellana, París, Librería de Don Vicente Salvá.

SAntamaríA, Francisco Javier (1943): Diccionario general de americanismos, México, D.F, Editorial P. Robredo.

SANTAMARÍA, Francisco Javier (1974): Diccionario de mejicanismos, México, Porrúa.

TERREROS Y PANDO, Esteban de (1786-1793): Diccionario castellano con las voces de ciencias y artes, Madrid, Imprenta de la viuda de Ibarra, hijos y compañía.

VARELA, Félix (1832): «Gramática de la lengua castellana según ahora se habla, ordenada por D. Vicente Salvá. París, año de 1830», Revista Bimestre Cubana, II, .6, pp. 118. 